\title{
Design and experimental investigation of adryer with two types of combined solar concentratorsusing two natural heat- transfer fluids
}

\author{
${ }^{\# 1}$ DRISS SLIMANI ${ }^{\# 2}$ BACHIR ELKIHEL ${ }^{* 3}$ GEORGES DESCOMBES \\ $*^{3}$ CHRISTELLE PERIIHON \\ ${ }^{*}$ Mohamed first University, Engineering School of Applied Sciences, Oujda , Morocco \\ ${ }^{1}$ d.slimani@ump.ac.ma, \\ 2belkihel@yahoo.fr, belkihel@ensa.ump.ma \\ ${ }^{*}$ Cnam, laboratoryMolecular Chemistry, Chemical Process Engineering and Energetics, Paris, France \\ 33eorges.descombes@lecnam.net, \\ ${ }^{3}$ christelle.perilhon@lecnam.net
}

\begin{abstract}
In this experimental study, a new solar dryer has been designed and manufactured by combining a concave solar concentrator with a series of convergent lenses whose concentrated radiation are reflected on the same absorber. Our main goal for this combination is to reduce the thermal losses by increasing the receiver bottom temperature. In our dryer, the receiver design uses air and water as the heat transfer fluid; these two fluids are heated and sent a heat exchanger to raise the drying air temperature. Furthermore, in order to improve the thermal performance, our approach is based on some techniques such as; the combination of two types of solar concentrators, simultaneous use of two natural heat transfer fluids, tilting concentrators, the insertion of obstacles at the absorber, and a specific solar tracker for explosive atmosphere. Our dryer has been tested for the first time in gas filling plant in Morocco for drying painted gas cylinders. The experimental results show that compared with flat-plate solar collector, the proposed dryer can significantly improve the performance in terms of air drying temperature. In fact, our solar dryer has reduced the drying time from $\mathbf{4 2 0}$ seconds to just $\mathbf{4 0}$ seconds and has improved drying air the temperature from $40{ }^{\circ} \mathrm{C}$ to $65^{\circ} \mathrm{C}$. Also, the health risks of workers have been reduced and the number of painted bottles has been increased by more than $43 \%$.
\end{abstract}

Keywords - Solar dryer, Combined solar concentrators, Two naturel heat transfer fluids, Thermal losses, Obstacles

\section{INTRODUCTION}

The most important property of the solar energy is a renewable energy resource. The average annual sun exposure in Morocco is about 2500 hours; it receives a daily solar energy of 16.2 to $27 \mathrm{MJ} / \mathrm{m}^{2}[1]$. The drying consumes about 12 to $25 \%$ of the total primary energy demand [2]. The solar energy is an area to study extremely in drying due to they are easily applicable.Therefore,this energy appears to be the energy of the future $[3,4]$.One of the advantages of this energy is its aptitude to be transformed into heat. The solar collector constitutes the major component of any solar system [5].Hot air is obtained from these collectors, and they are used in space heating [6,7], product drying [8,9], greenhouse heating [10] and pre-heating in ventilation systems $[11,12]$.

The parabolic solar concentrator is often used with systems for solar absorption refrigeration that can achieve temperatures over $100^{\circ} \mathrm{C}[13,14]$. Thus, the environmental problems related to the emission of greenhouse gases will be reduced[15].

The activity of painting gas cylinders is expanding in Morocco. The company, Salam Gas, recorded an increase in this activity of $1700 \%$. Despite,this important evolution, drying is done naturally and at ambient temperature. However, this traditional drying generates two major drawbacks. First, the customer expectations in terms of time, quality and quantity are not met. Second, in terms of employee health, exposure to high concentrations of solvents can cause loss of medium-term and long-term knowledge, causing behavioral changes, affecting mood and memory [16, 17].

To overcome these drawbacks, in this work and for the first time in this industry, we propose a solar dryer by combining a concave solar concentrator with a series of convergent lenses whose concentrated radiation are reflected on the same absorber. Solar drying systems must be properly designed to meet the drying requirements, such as product quality and drying time. Several researchers have developed simulation models for natural convection and forced convection systems [18]. Solar air collectors are simple devices for air heating by utilizing solar energy for many applications that require low to moderate temperatures below $60^{\circ} \mathrm{C}$, such as 
drying and space heating. The principal types were classified as one pass, double duct, and two passes [19]. Recently, studies covering different types of collectors have been undertaken by several researchers. Hot air generation and drying applications were examined with their designs [20, 21]. A single-pass solar air collector [22] and a double-pass solar air collector [23, 24] were designed and experimentally analyzed for their performance.

In this paper, we present the experimental studies and design of a new solar dryer by using acombined parabolicsolar concentrator with a series of convergent lenses and using a specific solar trackerfor explosive atmosphere. Our main goal for this combination is to reduceheat losses at the absorber by adding convergent lenses end has to act on the temperature difference between the bottom of the receiver and the planar absorber.The idea is to increase the receiver bottom temperature by the additional thermal energy lenses.The receiver design uses air and water as the heat transfer fluid; these two fluids are heated and sent a heat exchanger to raise the drying air temperature. According to Benghanem [25], both the orientation and tilt angles have significant effects on the magnitude of the solar radiation reaching the surface of a collector through solar tracker and forced convection. Also, to improve thermal performance and achieve air temperature that can ensure rapid drying, we used three techniques, first, we combined parabolicsolar concentrator and a series of convergent lenses for the same absorber, wealso used twonatural heat transfers fluids water and air at the same time, so these two fluids are heated and sent a heat exchangerto raise the drying air temperature. Second, the insertion of the obstacles inside the absorber, in addition while tilting the concentrators according to the latitude angle, and finally, the solar tracker realizedis specific to the explosive environment by using a pneumatic motor and a pneumatic control. Several experiments were conducted on a prototype designed and fabricated in a gas filling plant in Oujda (Morocco).The experimental results are provided and are compared with the performance of the dryer with flat collector [26].

\section{MATERIALS AND METHODS}

\section{A. System Design}

In this study, we used a solar dryer equipped with acombined parabolic solar concentrator and a series of convergent lenses, forced convection, and specific solar trackingfor an explosive atmosphere zone.Maximum power into the solar collector occurs when the surface is normal to the incident solar radiation.However, it is not always possible with fixed solar collector, since the relative position of the earth to the sun varies [27].This system (Fig.1, Fig.2 and Fig.3)was designed, fabricated and tested in a gas filling plant by the laboratoryin the Engineers National School(Mohamed First University Oujda, Morocco). The solar dryer comprised a concave solar concentratorhaving an area $6 \mathrm{~m}^{2}(3 \mathrm{~m} \times 2 \mathrm{~m})$ and 27 convergent lensesfor heating theair and waterat the same time. The receiver isconnected to a drying unitthroughacentrifugal fan with an airflow rate up to $2000 \mathrm{~m}^{3} / \mathrm{h}$ (Fig.4,Tab.1). The absorber tube was fixed on galvanized sheet metal;obstacles were inserted throughout the absorber tube for improved air heat exchange. The absorberwas coated with black paint to absorb the incident solar radiation. Thedrying system used was the subject of some improvements, in particular, the insertion of obstacles on both sides of the absorber (Fig.5). The air is preheated at the absorber, afterits temperaturewill be increased at the exchanger (steam/air)at the exit of the receiver. The concave solar concentrator was tilted to an angle about $34^{\circ}$ horizontally, which is considered an optimum angle for year-round performance of the system at Oujda[1]. When solar rays hit a surface at an oblique angle, the rays are more spread out [28]. The system was oriented to face the east to maximize the incident solar radiation on the collector. The automatic operation of the dryer with the beginning of the painting cycle has led to the reduction of heat loss and improving the dryer thermal performance.A detailed numerical and experimental analysis of such an optical design system with $3 \mathrm{~m}$ focal length and $1.8 \mathrm{~m}$ effective aperture was performed in a previous study.

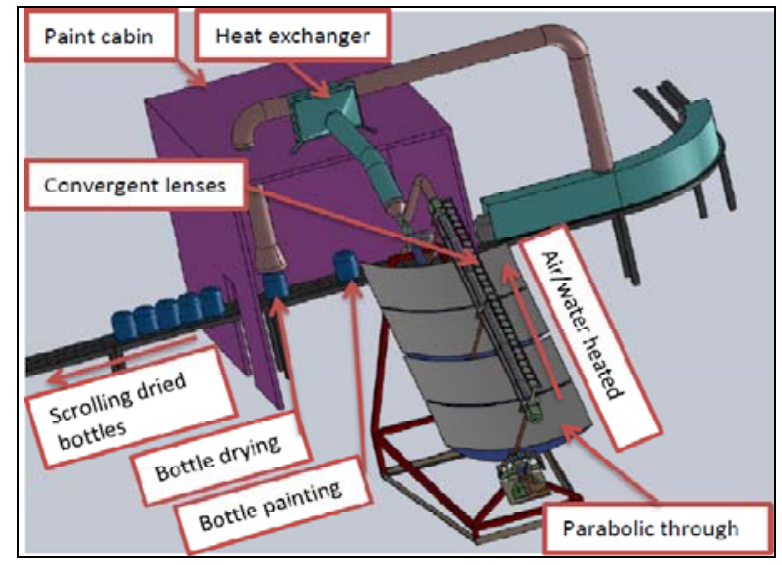

Fig.1. Schematic view of the solar dryer used for painted gas cylinders 

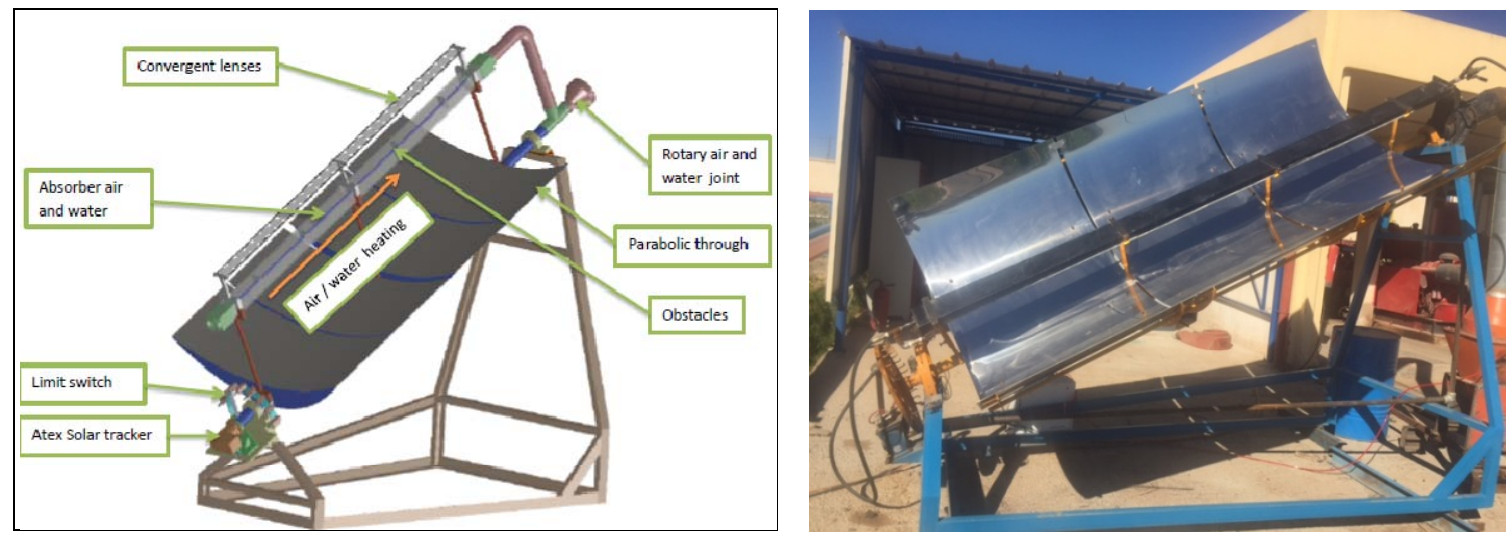

Fig.2. Schematic of the two concentrators combined

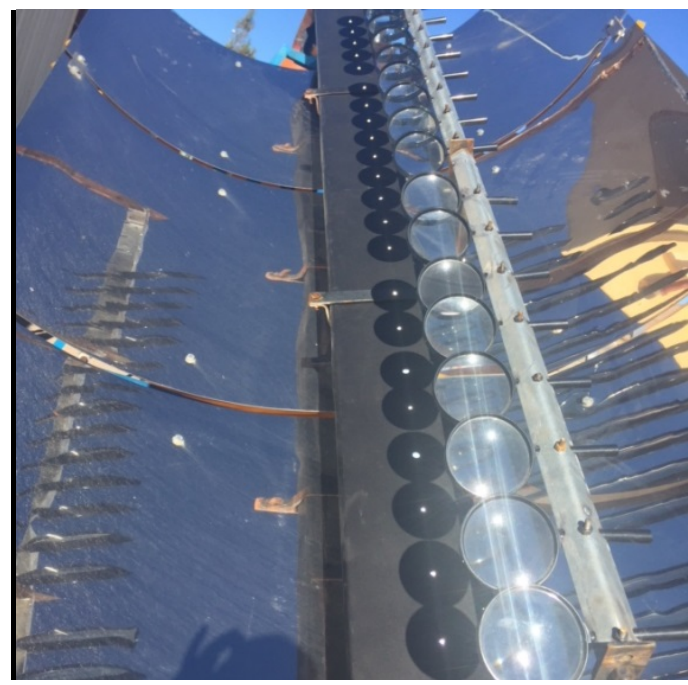

Fig.3.Realization of the combination of parabolic concentratorand convergent lenses

TABLE I. The concentrator'scharacteristics

\begin{tabular}{|l|l|l|}
\hline \multicolumn{1}{|c|}{ Components } & \multicolumn{1}{c|}{ Dimensions } & \multicolumn{1}{c|}{ Values } \\
\hline Concentrator & length, L & $3 \mathrm{~m}$ \\
& Width, Lar & $1.8 \mathrm{~m}$ \\
& Opening area & $5.1 \mathrm{~m}^{2}$ \\
\hline Absorber & Thickness of the glass, $\mathrm{e}$ & $0.005 \mathrm{~m}$ \\
& Height obstacles, $\mathrm{h}_{\text {as }}$ & $0.04 \mathrm{~m}$ \\
& Distance between obstacles, $\mathrm{b}$ & $0.1 \mathrm{~m}$ \\
& absorber tube diameter, $\mathrm{d}$ & $0.012 \mathrm{~m}$ \\
& absorber tube length, La & $9 \mathrm{~m}$ \\
\hline Convergent lenses & Diameter number & $90 \mathrm{~mm} 27$ \\
\hline
\end{tabular}

\section{B. Hot Air/Water Production Unit}

The collector is orientated in a north-south direction and tracking the sun from east to west. The stainless reflector surface of $6 \mathrm{~m}^{2}$ focuses the sun's radiation ona receiver canal, called a solar absorber, along the focal line of reflector length of $3 \mathrm{~m}$. A series of 27 convergent lenses focus the radiation on the opposite part of the same receiver.

The absorber channel, having a rectangular shape, was made in galvanized sheet on which was fixed the water tube and was inserted crosswise (fig.05) and covered with a layer of black paint. The bottom of the absorbing channel is ordinary glass, allowing passage of the concentrated solar radiation to the focal plane within the channel.

Some modifications have been implemented to the absorber;the thermal oil has been replaced by air and water as HTF (heat transfer fluid), which are free of cost, nonpolluting, and the air has practically no operating temperature limit. The cross-section of the solar air/water receiver is shown schematically(fig.5).The new receiver implements a longitudinal flow design, where the temperature gain is obtained at the passage of air 
between obstacles, which circulates hot water.The hot air channel has a dimension of $150 \mathrm{~mm} \times 50 \mathrm{~mm}$ with a face glass.

The air is preheated at the absorber with two concentrators and then it will be sent to the air/water heat exchanger (fig.4)for superheating to a temperature of about $70^{\circ} \mathrm{C}$.

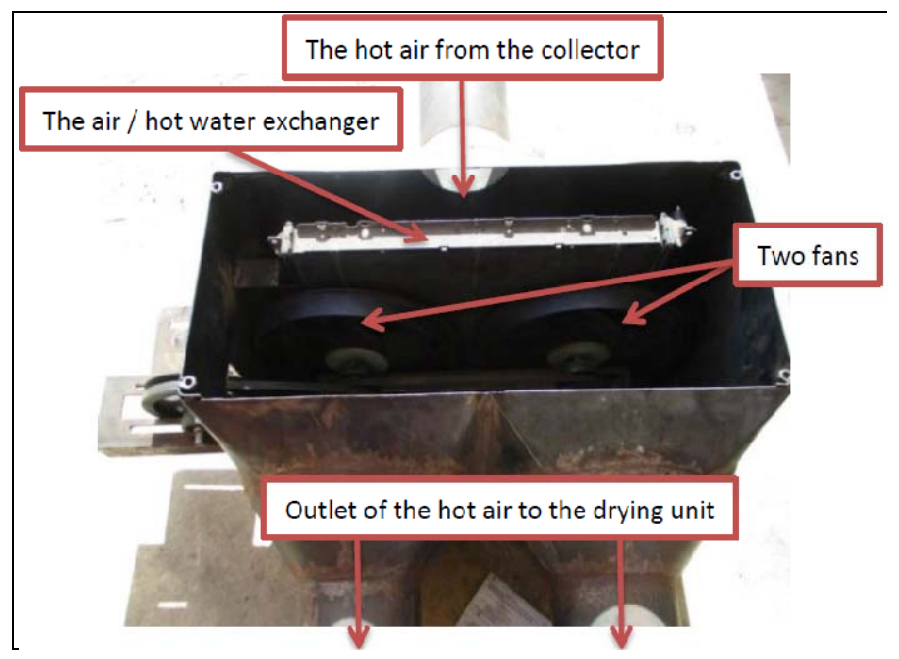

Fig.4.Air / water heat exchangerdeveloped

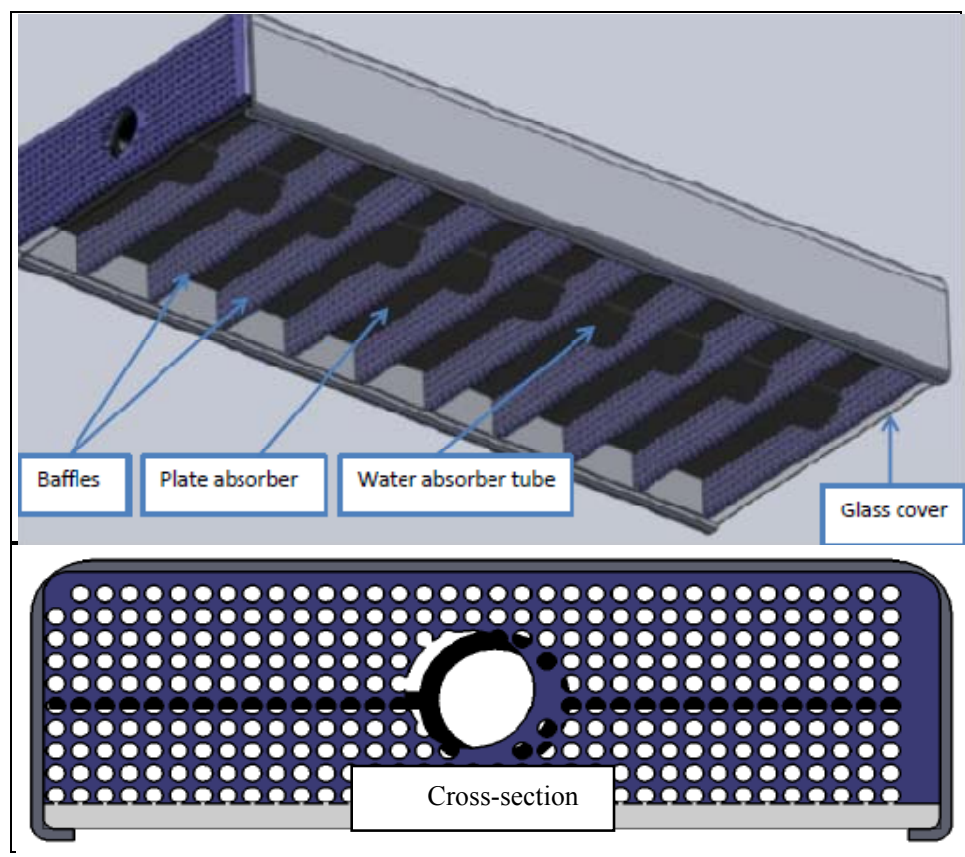

Fig.5.Schematic and cross-section of solar air/waterabsorberequipped with obstacles

\section{Experimental Procedure}

Painted cylinders transported by a motorized chain conveyor enter one by one into the drying unit. The fan is operated automatically with a speed adjusted to the optimum air during the drying experiments (fig.1).The air is preheated the first time during its passage through the obstacles fixed on the planar absorber and the hot water tube, and then these two natural fluids (air and water) will be sent to a heat exchanger to raise the temperature of the drying air up to $70{ }^{\circ} \mathrm{C}$. The air charged with solvents is discharged outside of the working environment using the paint booth extractor (fig.1). Quality paint has been tested manually and with the specific tape.

The hot water then passes through a condenser and circulates in a closed circuit by thermo-siphon-induced flow. The height position of the condenser, relative to the concentrator, ensures free passage of water in the absorber without the need to use a circulation pump rate in the solar receiver. The condenser is equipped with a safety valve, a pressure gauge, and a tap for the makeup water. 
The solar tracker used is specific to the explosive medium using a pneumatic motor and a pneumatic control.The control circuit is pneumatic and the limit has been provided at the beginning and end of the work day. Timers are adjustable, depending on the season,with the opportunity to order a manually rotating hub(fig.6).

The timing for drying should be equal or inferior to 40 seconds to obtain the desired result. The solvents content in each cylinder is about 0.01 liter. The measurement of temperatures, solar radiation, and air speed is done every 15 minutes. The drying operation starts at 08:30 and stops at 15:30.
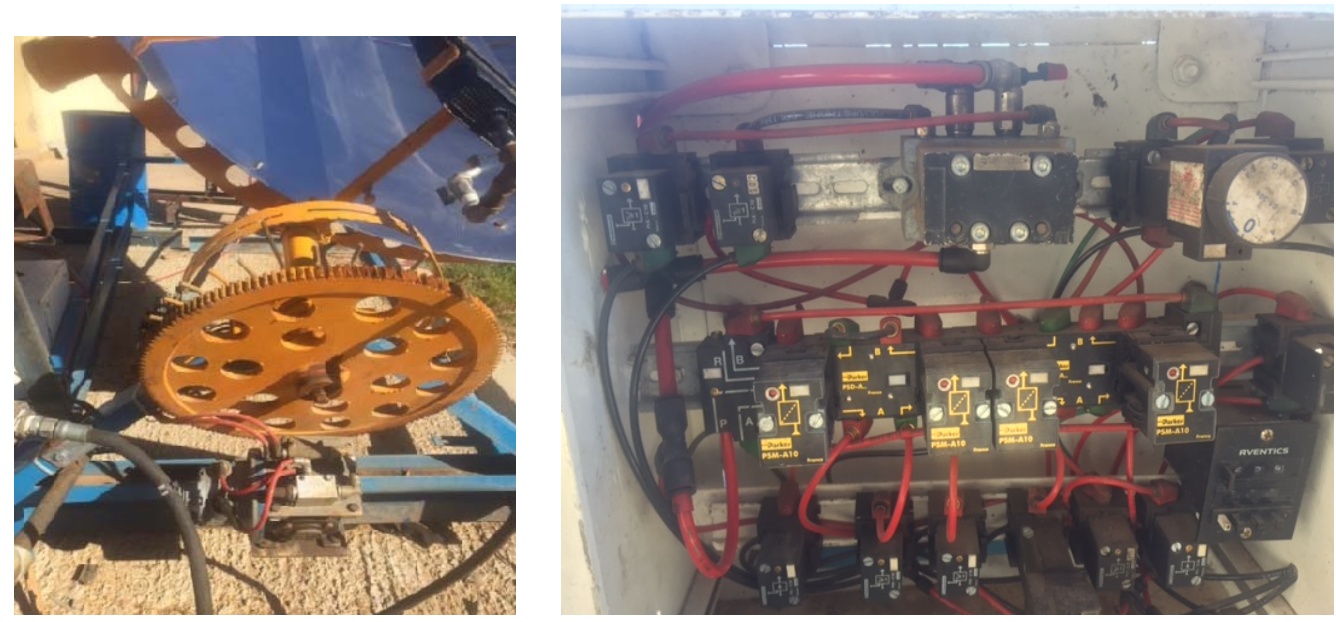

Fig.6.Sun tracking system developed with its pneumatic control box

\section{System Analysis}

The dimensions of the solar concentrator and the energy produced by the solar collector were calculated with the help of the following equations.

Concentration ratio is based on the concept of surface:

$\mathrm{Cg}=\frac{S c}{S r}$

Distance focal line (fig. 7)

$\mathrm{f}=\frac{r^{2}}{(4 \mathrm{xh})} r=\frac{\mathrm{AB}}{2}$

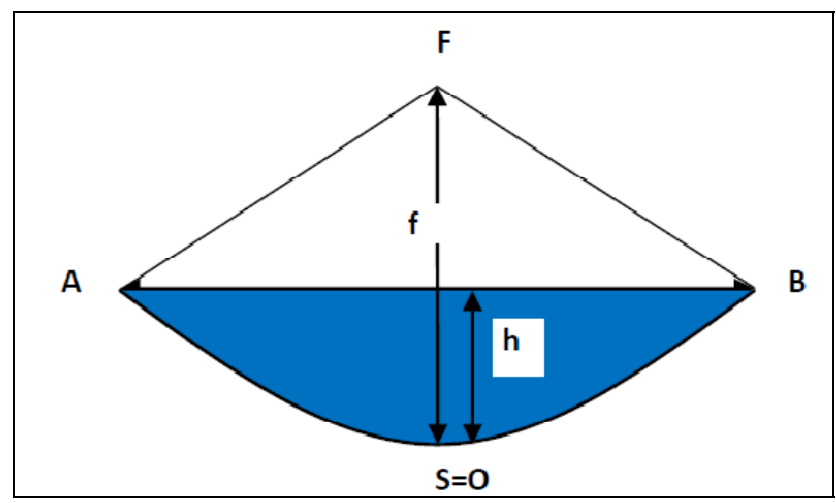

Fig.7.Parabolic cross section of the collector

The power output is the power recovered by the collector at the absorberlevel; it can be determined by the following expression:

$\mathrm{Qu}=\mathrm{f}_{\mathrm{r}} \times[$ Ic. $\rho \cdot \tau \cdot \alpha \cdot \gamma-\mathrm{UL} \cdot \mathrm{Sr} \times(\mathrm{Te}-\mathrm{Ta})]$

$\mathrm{Qu}=\mathrm{Qa}-\mathrm{Qp}$

Thermal losses reduce the energy received in the opening of a cylindrical parabolic concentrator; the power consumption is expressed as follows,Qp: Power corresponding to thermal losses

Qa $=$ Ic. Sr. $\tau . \alpha . \rho$

The losses Qp.rat the receiver are determined by the expression:

Qp.r $=$ hcv.Sr. $(\mathrm{Tr}-\mathrm{Ta})$ 
These thermal losses are proportional to the surface of the receiver and the temperature difference (Tr-Ta) between the absorber surface and the ambient temperature.Our goal is to reduce this difference by adding convergent lenses that send concentrated radiation back to the bottom of the absorber and this to increase Ta.

For calculating the outlet heat transfer fluid temperature, the following equation was used:

$\mathrm{Ts}=\mathrm{Te}+\frac{\mathrm{Qu}}{\mathrm{Cp} \cdot \dot{\mathrm{M}}}$

Energy production in solar collector can be found by the following equation:

$\mathrm{En}=\mathrm{Pn} \times \mathrm{t}_{\mathrm{d}}$

$\mathrm{P}_{\mathrm{n}}=\rho_{\mathrm{a}}\left(\mathrm{h}_{\mathrm{s}}-\mathrm{h}_{\mathrm{a}}\right) \mathrm{D}_{\mathrm{s}}$

Calculating the air enthalpy by using the Mollier chart

The energy amount crossing through the sun to the collectoris calculated as above with complex formulas or can be momentarily measured with a solar meter [10].

\section{EXPERIMENTAL RESULTS AND DISCUSSION}

A solar dryer has been manufactured and tested in a butane gas filling plant (Oujda, Morocco).This dryer will be used for drying gas bottles after washing and after painting in a short time.The bottles pass one by one automatically under the drying unit. The drying air velocity was fixed at $0.9 \mathrm{~m} / \mathrm{s}$. the dryer performance was tested in three days; the dryer was tested in an environment with average relative humidity $30 \%$ and average ambient temperature $25^{\circ} \mathrm{C}$.

\section{A. Solar Radiation and Ambient Temperature Values}

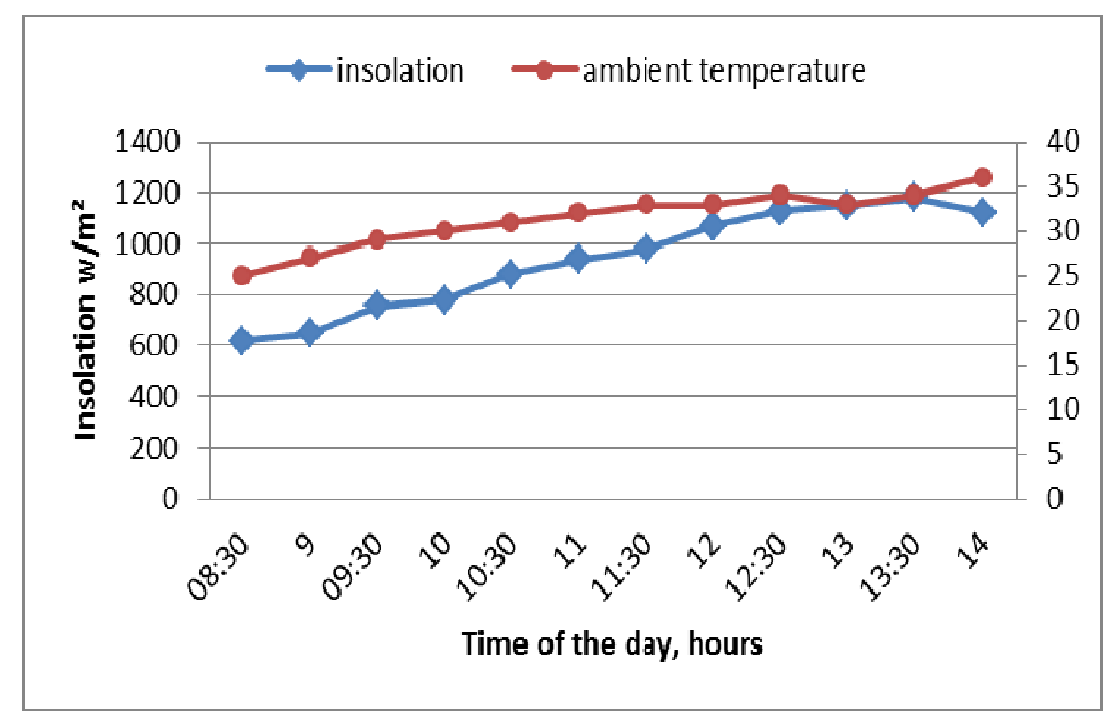

Fig. 8.Variation of the ambient temperature and the insolation during a day in September2017

The change of solar radiation and ambient temperature on September 2 is shown in Fig.8. A solar maximum intensity $1200 \mathrm{~W} / \mathrm{m}^{2}$ was observed at an ambient temperature of $35^{\circ} \mathrm{C}$. It increases from the sun rising to reach a maximum at mid-day before decreasing again until cancelling at night. The use of solar energy is well adapted to the applications for which the needs coincide with the sunniest hours. 


\section{B. The Impact of the Simultaneous Use of Two Natural Heat Transfer Fluids}

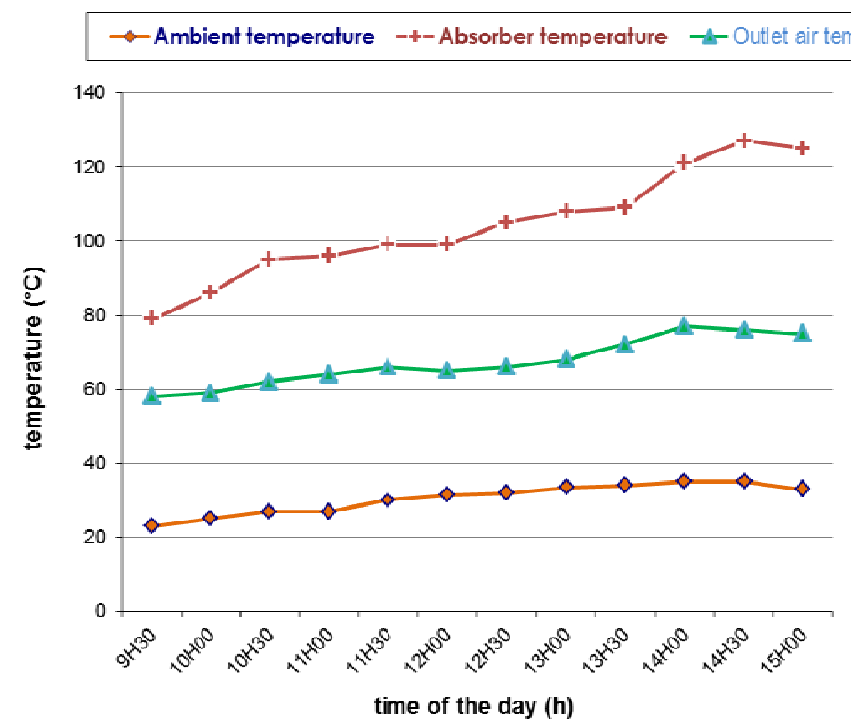

Fig. 9. Drying air temperature.

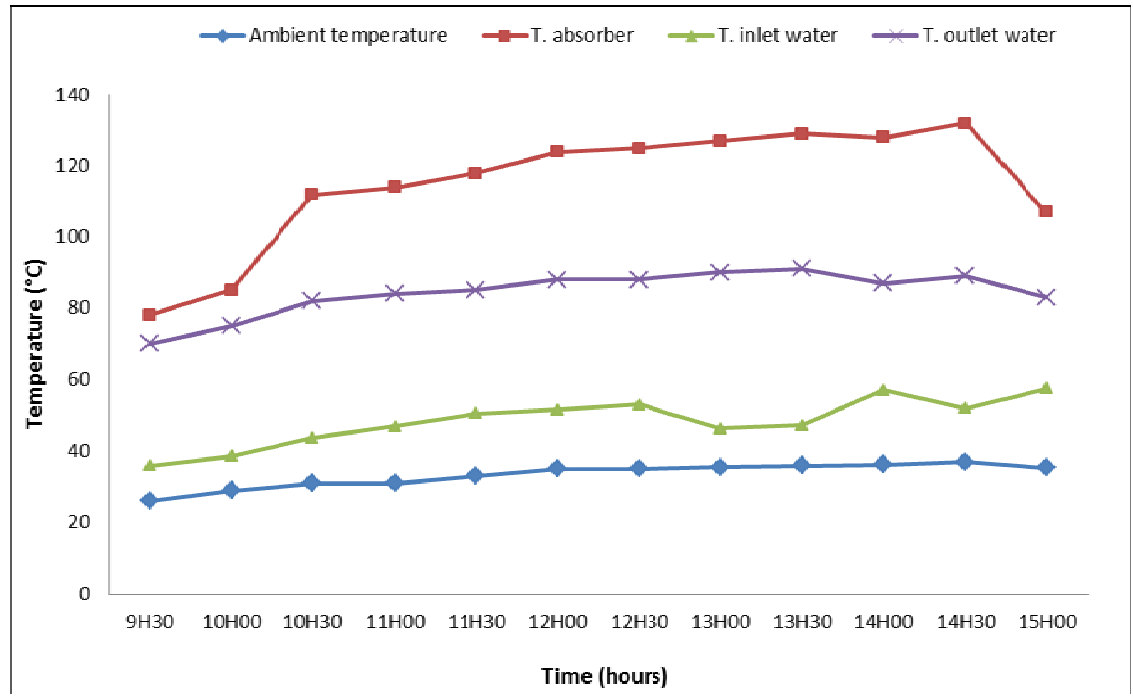

Fig. 10. Inlet-outlet water temperature in absorber.

As seen in Fig.9 and Fig.10, by using exchanger air/water and two heat transfer fluids, the drying air temperature has improved on average by $05^{\circ} \mathrm{C}$. However, the use of obstacles throughout the absorber allowed the improvement of the drying air temperature. The maximum temperature of the drying air recorded during hours of peak sunlight was $75^{\circ} \mathrm{C}$.

The average drying air temperature recorded was $65^{\circ} \mathrm{C}$, the high temperature of the absorber and high convective and radiative heat transfer.The water circulates in a closed circuit and the temperature at the receiver inlet is high in addition to the thermal insulation of the hot water circuit, and this is responsible for the rise in the air temperature. 


\section{Effect of Convergent Lenses on Rise of Receiver Temperature}

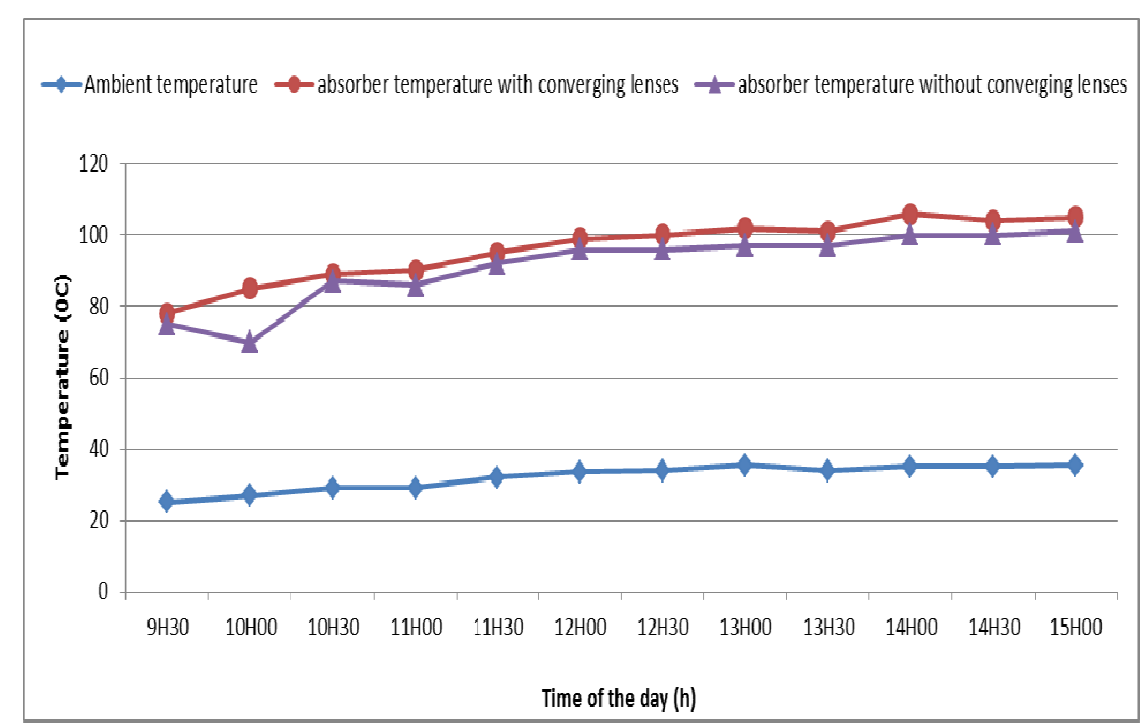

Fig. 11.Lenses impact on the absorber temperature

We find in Figure 11, the improvement of the absorber temperature Ta by the combination of convergent lenses having only a surface of $0.79 \mathrm{~cm}^{2}$ with the parabolic concentrator. Given these results, it is planned to put Fresnel lenses having a surface area of $40 \mathrm{~cm}^{2}$ to increase the absorber temperature Ta and thus reduce heat losses at the receiver.

\section{Effect of Drying Air Temperature on Drying Time}

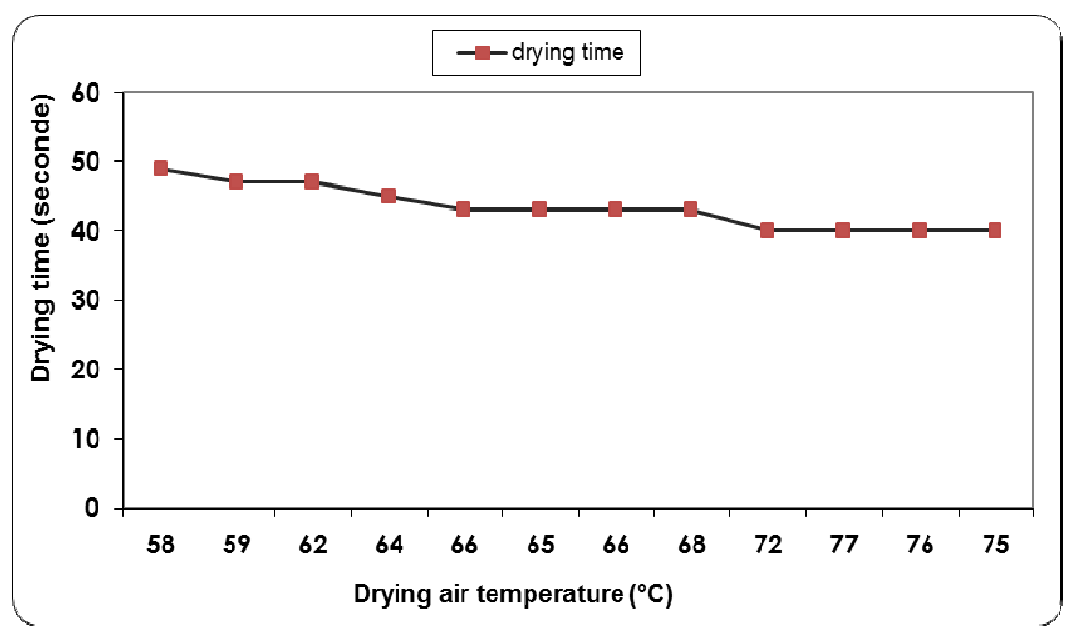

Fig. 12. Drying time with solar dryer.

Fig. 12 represents the temperature variation according to time in the drying unit for an optimum airflow $\left(500 \mathrm{~m}^{3} / \mathrm{h}\right)$. There was a significant reduction in the drying time from 420 seconds natural with dryingto about 40 seconds using our solar dryerand without the need to store the painting cylinders on the floor. The performance of the painting activity was increased by over $40 \%$, the number of painted cylinders per day increased from 3000 to 4300 , an increase of $43 \%$.

\section{CONCLUSIONS}

A forced convection solar dryer using a parabolic concentrator combined with a series of convergent lenses, the whole is tilted at an angle of $34^{\circ}$. This dryerwas designed, fabricated, and tested for drying painted gas cylinders. Firstly, our work demonstrates the impacton the dryer performances by the combination of two types of concentrators on a single receiver, and the first use of a solar dryer in the gas cylinder paint industry. Secondly, dryer performances were improved by tracking the sun and by inserting obstacles in the absorber. We also deduce the simultaneous use of two natural heat exchange fluids (air and water) resulted in the improvement of the drying air temperatureand reaches $65^{\circ} \mathrm{C}$. The maintenance of a good performance during the day is ensured by the inclination of concentrators at a $34^{\circ}$ angle,the sun is tracked by a pneumatic tracker developed by us and which is specific for an explosive environment. 
Accordingly, 420 seconds of drying under natural conditions decreased to 40 seconds with the developed dryer. The solar dryer has enabled the drying of painted cylinders on the conveyor and without the need to file them down and go directly to the filling unit. This led to a significant $43 \%$ increase in the number of painted bottles per day.On the health and safety side, employees are not exposed to solvents, since the bottles are dried inside the paint booth, which evacuates drying air to the outside.In perspective and given the results obtained, we will increase the Fresnel lens surface from $0.79 \mathrm{~cm}^{2}$ to $40 \mathrm{~cm}^{2}$.

\section{ACKNOWLEDGMENT}

This research work was funded by the company Salam gas, Morocco.

\section{NOMENCLATURE}

C: concentration factor

Cp: specific heat (J/kg.K)

$\mathrm{D}_{\mathrm{s}}$ : Air flow $\left(\mathrm{m}^{3} / \mathrm{s}\right)$

$\mathrm{f}_{\mathrm{r}}$ : Overall fluid-absorber transfer coefficient

ha: ambient air enthalpy, $(\mathrm{J} / \mathrm{kg})$

hs: heated air enthalpy, $(\mathrm{J} / \mathrm{kg})$

I: the energy gained from the total radiation

strikingthe collector surface $\left(\mathrm{W} / \mathrm{m}^{2}\right)$.

$\mathrm{L}$ : concentrator length (m)

Qu: amount of heat generated at the collector (w),

$\mathrm{P}_{\mathrm{n} \text { : }}$ power required $(\mathrm{W})$

Sc: concentrator area $\left(\mathrm{m}^{2}\right)$

Sr: Receiver area $\left(\mathrm{m}^{2}\right)$,

$\mathrm{t}_{\mathrm{d}}$ : drying time (s)

Te : collector inside temperature, $(\mathrm{K})$ $\beta$ : Angle between the reflected ray of the sun

and the center of normal opening

$\tau$ : transmission coefficient

$\mathrm{f}$ : focal distance $(\mathrm{m})$

$\mathrm{K}(\theta)$ : Incidence angle changed

$\gamma$ : Interception factor

$\rho$ : Monochromatic reflection coefficient

$\alpha$ : Absorption coefficient

$\tau$ : transmission coefficient

$\sigma:$ Standard deviation of the normal flow

$\rho a$ ambient air density, $(\rho \mathrm{a}=1,2 \mathrm{~kg} / \mathrm{m} 3)$

$\mathrm{U}_{\mathrm{L}}$ : Thermal losses coefficient $\left(\mathrm{W} / \mathrm{m}^{2} \mathrm{~K}\right)$

Ts: collector outside temperature, $(\mathrm{K})$

\section{REFERENCES}

[1] L. Bennamoun, and A.Belhamri,“Contribution to the feasibility study of solar dryers for agricultural products",Renewable Energies Review, CER07, 201-204, 2007.

[2] R.B. Keey,"Drying of losses and particule materials”,Hemisphere Publishing Corporation, pp. 1-2, 1992.

[3] A.Teyeb, L.Dehmani, A. Ben Ezzine, C.Kerkeni, and C.Kaabi,"Study of the performance of a through storage cocentrator",Renewable Energies Review 9, 135-141, 2006.

[4] M. Balghouthia, M.H.Chahbani, and A.Guizani, "Feasibility of solar absorption air conditioning in Tunisia",Building and Environment, 43. 1459-1470,2008.

[5] R. Bader, A.Pedretti, and A.Steinfeld.“A 9-m- aperture solar parabolic trough concentrator based on a multilayer polymer mirror membrane mounted on a concrete structure",Journal of solar energy Engineering, 133. 031016, 2011.

[6] RET Screen,(2004). Chapter; solar air heating project analysis, clean energy project analysis textbook, catalogue no: M39-100/2003Epdf. International Clean Energy Decision Support Centre, Canada. <www.retscreen.net/download.php/ang/119/0/Textbook_SAH.pdf>

[7] C. Christensen, (1998). Federal energy management program: transpired collectors (solar preheaters for outdoor ventilation air). $<\mathrm{http} / / /$ www.eere.energy.gov/femp/pdfs/FTA_trans_coll.pdf $>$.

[8] MA. Karim, andMNA Hawlader,"Development of solar air collectors for drying applications",Energy Convers Manage, 45,329-44, 2004.

[9] A. Fudholi, K. Sopian, MH.Ruslan, MA.Alghoul, and MYSulaiman,."Review of solar dryers for agricultural and marine products",Renew Sust Energy Rev,14(1), 1-30, 2010.

[10] H.Benli, and A. Durmus, "Performance analysis of a latent heat storage system with phase change material for new designed solar collectors in greenhouse heating",Sol Energy 83, 2109-19, 2009.

[11] S. Sokhansanj, and GJ.Schoenau,"Evaluation of a solar collector system with thermal storage for preheating ventilation air in farm buildings",Energy Convers Manage 32(2), 183-9, 1991.

[12] S. Cordeau, "The performance of a solar air pre-heater system for the ventilation of two commercial poultry barns", Master Thesis, Department of Bioresource Engineering McGill University, Montreal, Canada, 2010.

[13] W. Chekirou,N. Boukheit, and T. Kerbache,"Different modes of heat transfer in an absorber of a solar parabolic trough concentrator",Tlemcen: Review of Renewable EnergiesICRESD-07, p.21-28, 2007.

[14] A. Gama, M. Haddadi, and A.Malek,"Study and realization of a solar parabolic trough concentrator with blind solar tracking",Review of Renewable Energies11, 437-451, 2008.

[15] R. Blair, G. Calota, A. Crossman, F. Drake, and K. O'Keefe. "Design of a solar powered fruit and vegetable dryer", 2007.

[16] JR. Beach, J. Raven, C. Ingram, M. Bailey, D. Johns, EH. Walters, and M. Abramson,"The effects on asthmatics of exposure to a conventional water-based and a volatile Organiccompound-free paint”,EurRespir J 10, 563-566, 1997.

[17] A. Pronk, L. Preller, M. Raulfheimsoth, and IC. Jonkers,"Respiratory symptoms, sensitization, and exposure response relationship in spray painters exposed to isocyanates",Am J RespirCrit Care Med1, 1090-1097, 2007.

[18] S. Youcef-Al, andJ.Y. Desmons,"Numerical and experimental study of a solar equipped with offset rectangular plate fin absorber plate",Renewable Energy, 31:2063-2075, 2006.

[19] FK. Forson, MAA. Nazha, and H. Rajakaruna,"Experimental and simulation studies on a single pass, double duct solar heater",Energy Conver Manage, 44:1209-27, 2003.

[20] O. Turgut, and N. Onur,"Design and performance of a special solar collector and its application to drying of agricultural products",Gazi University J Sci, 13(3):639-48, 2000. 
[21] AME. Momin, JS. Saini, and SC. Solanki,"Heat transfer and friction in solar air heater duct with V-shaped rib roughness on absorber plate"Int J Heat Mass Transfer, 45(16):3383-96, 2002.

[22] H. Bulut, and F.Durmaz,"Designing, manufacturing and experimental analysis of solar air collector", I. National solar and hydrogen energy conference, UGHEK'2006, Eskisehir, Turkey, 21-23, June 2006.

[23] A. Fudholi, K. Sopian, MH. Ruslan, MA. Alghou, MY.Sulaiman, and MY.Othman,"Thermal efficiency of double pass solar collector with longitudinal fins absorbers",Am J ApplSci, 8(3):254-60, 2011.

[24] Ho CD, HM. Yeh, and TC. Chen. "Collector efficiency of upward-type double pass air heaters with fins attached",IntCommun Heat Mass Transfer, 38:49-56, 2011.

[25] M. Benghanem,“Optimization of tilt angle for solar panel: case study for Madinah”,Saudi Arabia Applied Energy, 88:1427-1433, 2011.

[26] D. Jain, and R. Kumar,"Performance evaluation of an inclined multi-pass solar air heater with in-built thermal storage on deep-bed drying application".India Journal of Food Engineering, 65: 497-509, 2004.

[27] Honsberg C.(2008) Solar radiation. University of Delaware. http://www.eecis.udel.edu/ honsberg/Eleg620/02_Solar_radiation.pdf

[28] DJN. Gavin,Solar Energy Projects for the evil Genius, 1st edn. McGraw-Hill, Chicago,2007.

\section{AUTHOR PROFILE}

Driss Slimani is Energy Engineer, works asRegional Manager of the company Salam gas in the sector of gas cylinders filling and maintenance. His interest areas are Automation and Robotics, Hydraulics and Pneumatics Control, PLC, Renewable Energy and Apply Mechanics.

Dr. BachirElkihel working ashead of the Industrial Engineering at the Engineering School, UniversityMohamed First, Oujda, Morocco. Her interest areas are non-destructive control,sizing of structures, control materials,Vibration, Hydraulics and Pneumatics Control, Renewable Energy and Apply Mechanics.

Pr. Georges Descombes, is aDirector of the Turbomachinery and Engine Laboratory, Cnam, Paris, France. His interest areas are Energy and Exergy analysis, Automobile exhaust, Aerodynamic engines, biofuels andthermodynamics.

Pr. Christelle Perilhon, Turbomachinery and Engine Laboratory, Cnam, Paris, France. His interest areas are Energy and Exergy analysis, Turbomachinery, Gas turbines, Aerodynamic engines, biofuels and thermodynamics. 